\title{
Recorded fatal and permanently disabling injuries in South African manufacturing industry - Overview, analysis and reflection
}

\section{Hedlund, Frank Huess}

Published in:

Safety Science

Link to article, DOI:

10.1016/j.ssci.2013.01.005

Publication date:

2013

Document Version

Peer reviewed version

Link back to DTU Orbit

Citation (APA):

Hedlund, F. H. (2013). Recorded fatal and permanently disabling injuries in South African manufacturing industry - Overview, analysis and reflection. Safety Science, 55, 149-159. https://doi.org/10.1016/j.ssci.2013.01.005

\section{General rights}

Copyright and moral rights for the publications made accessible in the public portal are retained by the authors and/or other copyright owners and it is a condition of accessing publications that users recognise and abide by the legal requirements associated with these rights.

- Users may download and print one copy of any publication from the public portal for the purpose of private study or research.

- You may not further distribute the material or use it for any profit-making activity or commercial gain

- You may freely distribute the URL identifying the publication in the public portal 
Recorded fatal and permanently disabling

injuries in South African manufacturing industry Overview, analysis and reflection 
Recorded fatal and permanently disabling injuries in South African manufacturing industry Overview, analysis and reflection 
reflection

Frank Huess HEDLUND,

COWI; Parallelvej 2, DK-2800 Kongens Lyngby, Denmark. E-mail: fhhe@ cowi.dk ${ }^{\text {a }}$

Technical University of Denmark, (DTU/IMM) DK-2800 Kongens Lyngby, Denmark. E-mail fhh@imm.dtu.dk

${ }^{\text {a }}$ corresponding address

\section{Abstract}

Studies on occupational accident statistics in South Africa are few and far between, the most recent paper on the manufacturing sector was published in 1990. Accidents in South Africa are recorded in two systems: Exhaustive information is available from the insurance system under the Workmen's Compensation Commissioner (WCC) but to access it on a timely basis is difficult. The legislative system under the Department of Labour (DOL) provides coarse but timely recordings. Interpretation is not simple however; both systems have seen changes to reporting formats and inclusion criteria over time, which hinder trend analysis. Also, the recordings of the two systems are not comparable due to major scope differences. This paper examines the relationship between the recordings in the two systems. Juxtaposing data from both systems the recordings of fatal accidents are found to be in agreement, somewhat less so for permanently disabling accidents / incidents. The paper examines if effects of the popular practice of replacing permanent workers with contract workers is visible in the WCC statistics - firm conclusions cannot be drawn however, due to data shortcomings. Data inaccuracies are reviewed and it is argued that WCC registrations may comprise industries outside the Standard Industrial Classification (SIC) scheme for manufacturing. The quality of accident reporting in official publications began to deteriorate by mid-1990s. The largest problem, however, is that reporting has come to a standstill, by mid-2012 the most recent WCC statistical publication covers 1999.

Keywords: occupational accident reporting systems, compensation for occupational injury, accident statistics, incidence rates 


\section{Research highlights}

- Occupational accidents in South Africa are recorded in an insurance and a legislative system

- $\quad$ The recordings are not immediately comparable due to scope differences

- $\quad$ This paper juxtaposes data from both systems and finds they generally are in agreement

- DOL data may serve as a quick, crude but nevertheless reliable feedback instrument

- Since mid-1990s the standard of accident reporting has deteriorated, reliable data after 2000 are mostly absent. 


\section{Table of Contents}

1 Introduction $\quad 5$

2 Data sources $\quad 7$

$\begin{array}{lll}2.1 & \text { Introduction } & 7\end{array}$

2.2 The workmen's compensation system $\quad 7$

2.3 Department of Labour 8

2.4 Overview of WCC/DOL scope differences 9

$\begin{array}{lll}2.5 & \text { Exposure data } & 10\end{array}$

2.6 Changes to the South African State 10

3 Results $\quad 11$

3.1 Procedure 11

3.2 Accident data 11

3.3 Exposure data 14

3.4 Computation of accident rates 14

3.5 Trends in accident rates 15

4 Discussion 17

4.1 Despite unexplained variation in WCC data, recorded injures are in broad agreement with DOL data 17

4.2 Possible inflation in SAF data for manufacturing 17

$\begin{array}{lll}4.3 & \text { Evident inaccuracies and discrepancies } & 18\end{array}$

$\begin{array}{lll}4.4 & \text { Injury data reporting lag hampers ability to monitor } \\ \text { performance and guide preventive efforts } & 18\end{array}$

No clear evidence of effects of labour market
restructuring 
Recorded fatal and permanently disabling injuries in South African manufacturing industry - Overview, analysis and

reflection

$5 \quad$ Conclusion

$6 \quad$ Acknowledgements

7

References

23

New SA Accident stats-24-sent w corrections.docx 


\section{Introduction}

There are very few studies on South African accidents statistics. The last paper on industry accident statistics was Leger and Macun (1990) who examined accident metrics published by the Workmen's Compensation Commissioner covering the period up till 1984. The current work fills a gap in the literature on South African injury epidemiology with an updated and a more comprehensive analysis for the period 1970-2010, using the number of injuries registered with two administrative systems and employment data from a third source, Statistics South Africa.

Accident statistics may serve as an important feedback instrument to monitor performance. The International Labour Organisation (ILO) acknowledge that the effective recording and notification of occupational accidents are instrumental in prevention. Statistics on occupational accidents may serve as a tool for measuring level of success in compliance, enforcement and preventive action (ILO 1996). Metrics based on length of absence from work are intrinsically unreliable. In comparison do statistics of fatalities and serious injuries provide more reliable indices of safety performance. This paper therefore deals with statistics on fatal and permanently disabling injury; it solely estimates incidence rates and examines trends. It also examines some of the general limitations of statistics on occupational accidents and outlines important scope differences and uncertainties for the South African case. The purpose is to provide a basis for an informed discussion on the safety performance of South African manufacturing, with a perspective on limitations of the data available.

Occupational accidents in South Africa are recorded in two systems: The insurance system, which for manufacturing is vested with the Workmen's Compensation Commissioner (WCC), and the legislative system under the Department of Labour (DOL). Interpretation is not simple, however. The recordings from the two systems are not directly comparable due to scope-of-inclusion differences. Furthermore, over time, there have been changes in definitions and reporting formats. The changes introduce variation in data that is unrelated to accident prevention performance and distort trend analysis. To overcome these complications, the paper juxtaposes data from both systems and employs multiple regression techniques to compute adjusted injury rates

The ILO publishes global estimates of occupational accidents by country (e.g. Takala (1999); Hämäläinen et al. 2006) - which encourage comparison and benchmarking. It has long been recognized however, that there are certain limitations to the various official accident statistics. Already four decades ago, the 
Lord Robens Committee (Robens 1972) noted that official accident statistics must be viewed simply as by-products of the information systems in use by the authorities, rather than as precise indicators of performance - cited reasons were that reporting criteria, incident classifications, and other categories differ from one system to another and even within a reporting system across time. Lord Roben's observation is still relevant. Jacinto et al. (2010) examined occupational accidents notification systems within the enlarged EU and observed that the lack of uniformity in EU databases and certain variations in data collection methods make comparability difficult.

The current work therefore provides background information necessary for detailed interpretation and contributes with a review of developments and changes in the DOL and WCC systems. The purpose is to aid meaningful comparability.

As already noted, studies on South African accidents statistics are scarce. The majority of studies concern the mining sector, which under apartheid had extreme injury rates (Leger 1992, Leger 1990, Eisner and Leger 1988a, 1988b). A seminal work was undertaken by the Commission of inquiry into safety and health in the mining industry (Leon Commission), which bluntly stated that self-regulation in the industry had failed (Leon et al. 1995). A more recent study by Murray et al. (2005) on an association between HIV infection and injury rate provides newer data with breakdowns on injury rates per age and calendar period. Recent studies for other sectors have not been identified. Some data were provided by Lerer and Myers (1994) who examined underreporting of fatal injuries in Cape Town; they provided a breakdown of underreporting per industrial sector. The last published paper on South African industry accident statistics was Leger and Macun (1990) covering the period up till 1984. 


\section{Data sources}

\subsection{Introduction}

Accident statistics are commonly expressed as rates, per unit population or per unit time worked. Computation of rates requires number of injuries (numerator figures) and exposure (denominator figures). Incidence rates express injuries in terms of number of persons exposed to the risk per year. Frequency rates express injuries in terms of hours of exposure taking into account actual exposure to the risk, e.g. including overtime hours. Severity rates express the number of days lost in terms of hours of exposure, taking into account the gravity of the injury. Rates can either be computed for (insured) employees or for workers (insured and uninsured combined). An important uninsured group is the self-employed.

\subsection{The workmen's compensation system}

The first law relating specifically to workmen's compensation in South Africa was passed in 1896 in Natal Province (the Employers' Liability Act, Natal) and prior to the Union in 1910 similar legislation was also in existence in other provinces. The first Union law to make provision for workmen's compensation came in 1911 (Native Labour Regulation Act). It provided for Black labourers only and the scope was very limited. In 1914, Parliament passed a Workmen's Compensation Act providing for death or accidental injury, but not for medical Aid. Act 59 of 1934 introduced compulsory insurance and provisions for medical aid and required employers to insure with any approved insurance company. It was succeeded by the Workmen's Compensation Act in 1941, which replaced insurance with private companies by a mutual insurance fund under the aegis of the State (Wiehahn 1980:10). The 1941 Act, although amended on 16 occasions, was to last for over 50 years until replaced by the Compensation for Occupational Injuries and Diseases (COID) Act no. 130 of 1993.

Since 1941, the Acts provide a system of fault-less compensation. Employees are entitled to compensation regardless of whether they contravene any laws or instructions or are acting without orders at all (e.g. COID Act no. 130 of 1993, sec 22). The main exception is in case of "serious and wilful misconduct" including drunkenness, which is only compensated if the injury is serious (ibid. sec 1). The main exclusions in the 1941 Act were 1) out-workers, who typically perform work at home, 2) employees with annual earnings above a certain 
ceiling, and, 3) domestic servants in private homes (Act no. 30, 1941:sec 3). The 1993 Act abandoned the wage ceiling and the exclusion of out-workers, but domestic workers are still excluded.

The State Accident Fund (SAF) introduced with the 1941 Act derives its income mainly from a levy on employers' annual wage bills and its administration is vested with the Workmen's Compensation Commissioner (WCC). Assessment rates are so determined that each class of industry shall bear its own cost of accidents, i.e. a system of experience rating with a variable tariff based on claims history. Certain employers are exempted from tariff assessments, including government departments, certain large municipalities, provincial administrations and the South African transport services; they pay for compensation from their own funds. All employers in the mining industry must register with the Rand Mutual Assurance Company (RMA) and those in the building industry with the Federated Employers' Mutual Assurance Company (FEMA). In total, accidents are registered with nine different funds. National accident statistics from these nine funds are annually compiled and published by the WCC.

Since 1941, the WCC statistics cover compensated accidents, which in broad terms are defined as being incurred during the course of employment (e.g. COID Act 1993, sec 22), and include road accidents. Even commuting accidents are included if the employer provides this service free of charge. Accidents that are reported to the various funds but cannot be compensated according to the Act are repudiated. Prior to the new COID Act in 1993, the repudiation category 'not a workman' would include out-workers and employees earning above the wage ceiling. Any compensation claims from independent contractors will also show in this category of repudiated cases.

Employers with the SAF are required to inform the WCC of the number of persons employed with them. Similar employment figures are not available from the other eight funds. For the SAF only, the WCC computes and publishes accident frequency rates for different branches of industry.

\subsection{Department of Labour}

The first Factories Act of 1918 required reporting of accidents, and accident statistics have been published in the Department's annual reports since the 1920s.

Reporting criteria for non-fatal accidents have changed over the period of interest. The Factories Act of 1941 required that accidents resulting in four or more days off work were reportable. That time threshold was changed with the Machinery and Occupational Safety Act (MOSA) of 1983 to 14 days or more off work (Leger and Macun, 1990). The DOL's annual reporting of "incidents" (before 1985 the term "casualties" was used, and around 2005 the term "nonfatal" appears) are not comparable to the permanent disablement figures published by the WCC. 
The present legislation requires that incidents are reported if they result in 14 days or more off work, result in death or permanent physical disability, if a dangerous substance was spilled, machinery fractured, amongst others. Reporting of traffic accidents on a public road or incidents in a private household are excluded (OSH Act No. 85, 1993, sec 24). The reporting criteria reflect the DOL's concern with prevention, as they also comprise incidents, which did not cause actual injury but had potential to do so.

As of 1985, the DOL aligned its accident reporting format with the international Standard Industrial Classification of all economic activities (SIC) system used by the WCC. Before the change the major breakdown categories were accidents related to non-factory and factory activities, the latter including "premises where machinery is used"1 (Annual Report 1984:90). The categories used before $1985^{2}$ therefore complicate a breakdown on manufacturing and non-manufacturing.

\subsection{Overview of WCC/DOL scope differences}

The scope differences are illustrated graphically in Figure 1. . The figure contrasts the accidents reportable to DOL and the fraction actually reported; and the number of accidents claimable from the WCC and the fraction actually claimed The total number of fatal accidents in the manufacturing industry is expressed as the sum of four categories: 1) road accidents arising out of work, 2 ) accidents to insured out-workers typically working at home, 3) accidents to insured employees working at company premises, and 4) accidents to the uninsured groups comprising the self-employed as well as cases repudiated in the compensation system.

It has been speculated that the "double burden" of reporting accidents with two different authorities may lead to under-reporting; if one authority is notified but not the other one. While reporting to the $\mathrm{WCC}$ is required to claim monetary compensation, reporting to the DOL is only a legal obligation which could place the employer under increased monitoring by the inspectorate (Leger and Macun 1990). Consequently, incentives for under-reporting of incidents to the DOL are evident.

\footnotetext{
1 The 1941 Act was criticized for being too restrictive in scope since it only covered persons employed in factories or worked in connection with machinery - not other commercial undertakings where injuries due to physical material handling were as likely as in factories. The name was furthermore misleading, the courts had in isolated cases interpreted it as being applicable to factories only; the general public was under the same impression (Wiehahn 1980:38)

2 Two changes affect reporting of DOL incidents. The SIC format change is a likely consequence of the Wiehahn Commission's recommendation that the DOL and the WCC reporting of accidents be streamlined and rationalised (Wiehahn 1980:39) and seems to have taken place in 1985 for both fatal accidents and incidents. The time threshold defining an incident was changed with MOSA of 1983 and may have affected the number of reportable incidents already in 1984.
} 


\subsection{Exposure data}

There are two major data sources of denominator data available in South Africa. The first is the employment statistics from Statistics South Africa, SSA (formerly the Central Statistical Service, CSS). The institution has published a quarterly Bulletin of Statistics (henceforth Bulletin) comprising employment data, typically for 3 consecutive years, for the entire period of interest. Employment figures are estimates based on a monthly sample survey of private manufacturing firms and comprise all executive, administrative, technical, production and related labourers. Seasonal and occasional employees, as well as employees absent on vacation or sick leave on full pay, are included. Working proprietors are not included (Bulletin, March 1971:28). From 1976 and onwards employment in manufacturing also include public corporations and Government undertakings (Bulletin 1981:2.32).

From 1987 to 1995, SSA (then CSS) also published the annual South African Labour Statistics (SALS). For this data series, census data were used to adjust the estimates from the monthly sample survey, a so-called adjustment for overand undercount. Employment data from SALS are therefore superior to Bulletin data in that they have longer time series of typically 15 years compared to typically 3 years, and that the series are adjusted to reflect the latest Census information. SALS data are not available for the entire period of interest though.

The second major source of employment data is the WCC annual statistics. As noted earlier, employers with the State Accident Fund report both earnings and number of employees to the WCC.

\subsection{Changes to the South African State}

For sake of completeness, both numerator and denominator figures are affected by changes to the South African State. Namibia became independent in 1990. In the late 1970s and early 1980s some Bantustans were declared independent by the South African government, specifically the so-called independent Republics of Transkei, Bophuthatswana, Venda and Ciskei (TBVC). They were reintegrated in South Africa in 1994. The former TBVC states were not very industrialised and potential inclusion errors are relatively small. For instance, total employment in manufacturing in Bophuthatswana, Venda and Ciskei amounted to 66,000 in 1991 , some $4.4 \%$ of total employment in the South African manufacturing sector (SALS 1995:2.182). - 


\section{$3 \quad$ Results}

\subsection{Procedure}

Reported injuries were taken from the annual Report on the Statistics of the WCC and the DOL Annual Reports from 1970 to the most recent publications available in January 2012. Early WCC reports were obtained from the archives of the Compensation House in Pretoria, more recent ones over the Internet and through personal contacts in the WCC. DOL Annual Reports were retrieved at the National Library in Pretoria and at the DOL Head Office in Pretoria. A few recent reports could not be retrieved despite repeated requests through multiple channels. Official employment statistics were taken from Bulletin and SALS releases available at the Statistics South Africa library, more recent data were available over the Internet. Accident and employment data are presented in Table_1.

\subsection{Accident data}

The WCC and DOL accident recording systems sample the same reality, albeit with different scope criteria, which change over time. Multiple regression techniques allow an examination of the degree of agreement between data in the two systems, i.e. of the level of internal data consistency and overall confidence in data.

Figure 2 shows the number of fatal accidents in the manufacturing sector for the period 1970-1999 reported to the WCC (All Funds) and the DOL. Unsurprisingly, due to the scope exclusion of road accidents, DOL numbers are lower than WCC figures. WCC statistics do provide information on accidents, which involve a vehicle ${ }^{3}$ but make no distinction if the accident takes place on a public road or on company premises. Only the former are excluded from DOL statistics. Excluding vehicle accidents would bring WCC registrations more in line with DOL scope, although the number of accidents excluded would be too large. Unexpectedly, the reduced WCC numbers are still higher than DOL numbers after 1985 (Figure 2).

The WCC numbers for 1979-1995 exhibit a marked variation when compared to DOL figures. A WCC official was unable to explain the higher variability,

\footnotetext{
3 , Categories "Automobile" and "Other vehicle" in table 9A3 and 9A4. Information is only available for All Funds, not specifically for SAF
} 
such as an irregular pattern of administrative procedure or other reporting system artefact. The variation has been attenuated by moving average techniques. Expectedly, the number of fatal accidents registered with DOL drop after 1984, coinciding with the SIC scheme reporting change. The number of accidents registered with WCC for 1999 is rejected, in part because the number is unusually low, in part because of an extreme number of repudiations that year (discussed later). DOL fatalities for manufacturing are not available for 1989.

To examine the level of internal data consistency the b-coefficients in the following model were estimated using multiple regression analysis

$$
[\mathrm{WCCF}-\mathrm{VEHF}]_{\mathrm{MOV} \_\mathrm{AV} 3}=\mathrm{b}_{1} \mathrm{DOLF}+\mathrm{b}_{2} \text { FORMAT }
$$

where

$\begin{array}{ll}\text { WCCF } & \begin{array}{l}\text { reported WCC fatal accidents (All Funds) } \\ \text { reported WCC fatal accidents (All Funds) involving a vehi- } \\ \text { cle } \\ \text { reported DOL fatalities }\end{array} \\ \text { DOLF } & \begin{array}{l}\text { index denotes three-year moving average (endpoints only } \\ \text { two-year) } \\ \text { MOV_AV3 }\end{array} \\ \text { FORMAT } & \begin{array}{l}\text { a dummy variable, set to 1 for 1970-1984, and 0 otherwise. } \\ \text { FOR }\end{array}\end{array}$

Model output is:

\begin{tabular}{lrc}
\hline & Coefficients & \multicolumn{1}{c}{$P$-value } \\
\hline b1 & 1.17 & $<0.000$ \\
b2 & -61.2 & $<0.000$
\end{tabular}

Adjusted R Squared $=0.946, \mathrm{n}=28$

A similar analysis was carried out on data for permanently disabling injury (Figure 3). The number of permanently disabling vehicle accidents registered with the WCC is very small, both compared to the total number of permanently disabling injuries and relative to the number of fatal vehicle accidents, leading to concerns if such accidents are correctly registered with this category. Consequently, no adjustment for vehicle accidents was made. As noted earlier, DOL registrations of incidents also comprise events which did not cause actual injury but had the potential to do so. The degree to which such events are registered can be sensitive to campaigns etc which can introduce systemic variation in reported DOL figures. The number of permanently disabling injuries registered with WCC for 1999 is rejected for the same concern about repudiations as stated for fatal accidents.

The b-coefficients in the following model were estimated using multiple regression analysis

$$
\mathrm{WCCP}=\mathrm{b}_{3} \mathrm{DOLI}+\mathrm{b}_{4} \text { FORMAT }
$$


where

WCCP

DOLI

FORMAT reported WCC permanently disabling injuries (All Funds) reported DOL incidents/casualties a dummy variable, set to 1 for 1970-1984, and 0 otherwise.

Model output is:

\begin{tabular}{lrr}
\hline & Coefficients & \multicolumn{1}{c}{$P$-value } \\
\hline b3 & 0.698 & $<0.000$ \\
b4 & -5642 & $<0.000$
\end{tabular}

Adjusted R Squared $=0.92, \mathrm{n}=28$

For fatal and permanently disabling injury the multiple regression equations [1] and [2] explain 95 percent and 92 percent of the variation respectively. The estimated number of WCC fatalities and permanently disabling injuries were computed using the regression equations ${ }^{4}$. For fatal accidents, there is a good agreement between estimated and observed WCC registrations, indicative of a good degree of internal consistency between the WCC and DOL systems. This is slightly less so for permanently disabling injury; large deviations occur for 1975 and 1984 (Figure 3).

To permit an estimation of WCC fatal accidents directly from the more stable DOL data the b-coefficients in the following model were estimated using multiple regression analysis

$$
\mathrm{WCCF}_{\text {MOV_AV3 }}=\mathrm{b}_{5} \text { DOLF }+\mathrm{b}_{6} \text { FORMAT }
$$

where

$\begin{array}{ll}\text { WCCF } & \begin{array}{l}\text { reported WCC fatal accidents (All Funds) } \\ \text { reported DOL fatalities } \\ \text { DOLF }\end{array} \\ \text { MOV_AV3 } & \begin{array}{l}\text { index denotes three-year moving average (endpoints only } \\ \text { two-year) }\end{array} \\ \text { FORMAT } & \begin{array}{l}\text { a dummy variable, set to } 1 \text { for 1970-1984, and 0 otherwise. } \\ \text { FOR }\end{array}\end{array}$

Model output is:

\footnotetext{
${ }^{4}$ As mentioned earlier, the wage ceiling provision was abandoned with the passing of the new COID Act in 1993. The category 'not a workman' in Table 2 comprises wage ceiling repudiations, amongst others. From the early 1970s to early 1990s, South Africa experienced inflation rates of about 10-15 percent. Some of the variation in number of repudiations within this category may be caused by cycles of inflationary wage increases followed by amendments to the 1941 Act to adjust the wage ceiling upwards. The cycles could suggest that a number of fatal and permanently disabling accidents may have been excluded from the WCC statistics due to an arbitrary wage ceiling provision. Multiple regression analysis on both data sets shows the correlation to be not significant $(\mathrm{P}>0.11, \mathrm{n}=28)$, and does not allow purging of wage ceiling effects.
} 


\begin{tabular}{lrr}
\hline & Coefficients & \multicolumn{1}{c}{$P$-value } \\
\hline b5 & 2.12 & $<0.000$ \\
b6 & -105 & $<0.000$
\end{tabular}

Adjusted R Squared $=0.946, \mathrm{n}=28$

\subsection{Exposure data}

Figure 4 shows the major sources of exposure data from the WCC, DOL and SSA systems for manufacturing. The DOL registrations of employment (discontinued in 1983) are markedly and consistently higher than Bulletin data. This reflects the particular "factories" reporting format used by DOL up till 1984 and is consistent with a higher number of DOL accidents for the same period. Surprisingly, WCC SAF employment data 1970-1980 correspond largely to DOL data, although WCC SAF has used SIC classifications for the entire period of interest. The WCC SAF employment numbers furthermore exhibit an unexplained increase in variability after 1980, similar to the onset of variability observed in WCC reported fatal accidents 1979-1995 5

Bulletin data evidently presents the lowest employment figures. This is remarkable for two reasons. First, Bulletin employment represents an upper estimate for the number of full-time employees, as no attempts are made to adjust the number of occasional, seasonal or part-time workers to a corresponding number of full-time workers. Second, WCC SAF figures do not cover the entire manufacturing section, only the (albeit large) subgroup of manufacturing companies that are with the $\mathrm{SAF}^{6}$.

\subsection{Computation of accident rates}

Bulletin data are, although likely on the high side, the best employment estimates available and the only source that covers the entire period of interest. Three series of fatal incidence rates pr 10,000 employees can now be computed. The first series is computed directly from WCC SAF registrations and covers 1970-1999, except for 1991-1993 where SAF employment data are absent. The

\footnotetext{
${ }^{5}$ The variability in the WCC SAF employment count and fatal accident count could be of minor importance if they correlated positively. In this case the effect on computed accident rates might be minimal. A Pearson statistical correlation analysis carried out on data 19791995, when the variation is substantial, suggests that employment and accident count are negatively correlated. The result ris not significant however ( $\mathrm{Prob}=0.76, \mathrm{n}=14$ ) so we must accept that they are not correlated at all. That conclusion does not change if the correlation analysis is carried out on data for the entire period 1970-1999.

${ }^{6}$ Firm employment estimates can be elusive. In the SALS data series, SSA would adjust employment figures when more precise census information were available. One of the larger undercount adjustments took place for 1986 with an upward adjustment of employment of 129,000 (9.9\%) (1987 and 1993 issues of SALS). Hence, the maximum uncertainty of measurement appears to be about 10 percent. This cannot explain the discrepancy between WCC SAF and Bulletin data.
} 
second series is computed for DOL registrations and Bulletin employment data. The third series is computed for WCC estimates using regression equation [1] and Bulletin employment data. Rates are shown on Figure 5

Similarly, three incidence rates series for permanently disabling injuries were computed. The first directly from WCC (SAF) registrations of injuries. The second for WCC (All Funds) injuries and Bulletin employment data. The third for DOL for reportable "incidents/casualties" and Bulletin employment data (Figure 6).

\subsection{Trends in accident rates}

To estimate trends in fatal accident incidence rates, the b-coefficients in the following model were estimated using multiple regression analysis

$$
\text { DOLFIR }=b_{7}+b_{8} \text { YEAR }+b_{9} \text { FORMAT }
$$

where

DOLFIR fatal incidence rate per 10,000 employees computed from DOL recordings and Bulletin employment

YEAR Year

FORMAT a dummy variable, set to 1 for 1970-1984, and 0 otherwise.

Model output is:

\begin{tabular}{lrr}
\hline & Coefficients & \multicolumn{1}{c}{$P$-value } \\
\hline b7 (intercept) & 31.3 & 0.020 \\
b8 & -0.0153 & 0.023 \\
b9 & 0.364 & 0.003
\end{tabular}

Adjusted R Squared $=0.81, \mathrm{n}=29$

Model output shows that the DOL fatal incidence rate has declined $(\mathrm{P}=0.02$, $\mathrm{n}=29$ ) over the period 1970-1999. The trend has been extrapolated to 2010 . All three available DOL data points for 2000-2010 are below the extrapolated trend lines as seen on Figure 5.

To estimate permanently disabling injury rends, the b-coefficients in the following model were estimated using multiple regression analysis

$$
\text { DOLIIR }=b_{10}+b_{11} \text { YEAR }+b_{12} \text { FORMAT }
$$

where

DOLIIR incidence rate per 10,000 employees computed from reportable DOL incidents/casualties and Bulletin employment

YEAR Year

FORMAT a dummy variable, set to 1 for 1970-1984, and 0 otherwise.

Model output is: 


\begin{tabular}{lrr}
\hline & Coefficients & \multicolumn{1}{c}{$P$-value } \\
\hline b10 (intercept) & 3,565 & 0.001 \\
b11 & -1.77 & 0.002 \\
b12 & 53.4 & 0.000
\end{tabular}

Adjusted R Squared $=0.93, \mathrm{n}=29$

Model output shows that the rate for reportable DOL incidents has declined $(\mathrm{P}=0.002, \mathrm{n}=29)$ over the period 1970-1999. Extrapolation of this trend is clearly unreasonable, as an incident rate of almost zero would be expected by 2010. All three available DOL registrations for 2000-2010 are below the extrapolated trend line as seen on Figure 6. 


\section{Discussion}

\subsection{Despite unexplained variation in WCC data, recorded injures are in broad agreement with DOL data}

The number of fatal accidents registered with the Workmen's Compensation Commissioner's (WCC) State Accident Fund (SAF) and with WCC All Funds exhibit a considerable and unexplained variation, in particular for 1979-1995. Despite the variation, multiple regression analysis demonstrates a good agreement between the number of fatal accidents registered with the WCC and the Department of Labour (DOL). This leads to overall confidence in the 19701998 data and permits estimation of revised WCC fatal incidents based on DOL data.

WCC permanently disabling injury data do not exhibit this kind of variation. Multiple regression analysis can only partly resolve the scope differences between the number of permanently disabling injuries registered with the WCC and the number of reportable incidents registered with DOL however, and can only demonstrate a fair agreement between the two data sets.

The last published paper on South African industry accident statistics was Leger and Macun (1990) covering the period up till 1984. Their sole data source was injury frequency rates (per million man hours worked) reproduced directly from the annual reports of the Workmen's Compensation Commissioner. The authors found no evidence that South African manufacturing industry was becoming safer over time - providing a counter example to the general decline in occupational injury rates observed in industrialized countries (Hämäläinen et al. 2006). This paper finds no support for this earlier conclusion.

\subsection{Possible inflation in SAF data for manufacturing}

SAF registrations of number of workmen are larger than official employment data from Statistics South Africa (SSA). The inflation is unexplained. Surprisingly, for 1970-1979, the SAF employment numbers appear in agreement with DOL employment registrations, although the DOL's "factories" scope was broader, comprising not only manufacturing but also premises where machinery was used. 
It raises the possibility that WCC injury registrations for the manufacturing sector are too generous and comprise industries that SSA consider outside the Standard Industrial Classification (SIC) scheme for manufacturing. The observation, that WCC fatal accidents adjusted for vehicle accidents exceed DOL registrations (Figure 2) further supports this possibility. If WCC injury registrations for SIC manufacturing are inflated, the use of Bulletin employment denominator figures will over-estimate accident rates. Alternatively, if the WCC accurately captures SIC manufacturing accidents, inflated SAF denominator figures will under-estimate accident rates. The data available does not allow a determination of which of the two options is the more accurate.

\subsection{Evident inaccuracies and discrepancies}

Manual preparation of large amounts of data is inherently error prone. It is impossible, that the accident count for All Funds is lower than for SAF, this was nevertheless the case in 1971, 1972, 1976 etc. Inconsistencies become more predominant in WCC reports from the mid-1990s. While data for the SAF seems reasonably accurate (except 1999) notable inconsistencies for All Funds appear in the 1993 report. All Funds data in the 1995 and 1997 reports are evidently unreliable, with entire rows and columns that obviously should be shifted down or right ${ }^{7}$. The 1999 report, the most recent by 2012, an unusually low number of reported accidents could be inaccurate due to an unexplained extreme increase in the number of repudiated cases. For instance, cases repudiated on the grounds "Not an accident (gradual onset etc)" increase from a normal level of 500-1,000 to almost 19,000 (see Table 2). The report is silent on the repudiations and the extent to which they may influence the number of registered accidents.

Beginning mid-1990s inconsistencies appear in DOL registrations (Table 3) exacerbated by frequent changes in the reporting format. In the 1998 report, previously reported numbers for 1996 and 1997 change without commentary. In 2004, the DOL shifted accident reporting to a newly created Labour Market Bulletin publication, the reporting format change yet again, and there are evident discrepancies in the 2003-2004 tabulations, differences of 35-300 percent go unnoticed. In later DOL publications, only aggregate injury data are presented, if reported at all, with 2008 being an exception.

\subsection{Injury data reporting lag hampers ability to monitor performance and guide preventive efforts}

The WCC's annual Reports on the Statistics are the only source of accident statistics in South Africa and are included in national statistics released by SSA. He does not publish incidence rates (divided by number of people working) but the more accurate frequency rates (divided by hours worked) that takes into account slight differences in number of hours worked per week per. In addition,

\footnotetext{
7 For instance, there are 349 fatal accidents for " Charitable, religious, political and trade organisations" in 1997, while the normal level of yearly fatalities in this sector is about 2-3.
} 
he reports severity rates, which are superior to incidence rates as they take injury severity into account, the number of days lost.

The WCC Reports on the Statistics present detailed tabulations of for example number of cases by location of injury (brain, scull, eye, etc) and tabulations of number of accidents by instrumental cause (machinery, hoists, etc.) with breakdowns per major industrial subgroups. The costs of accidents are also reported with a breakdown per sector. In addition, the reports hold detailed listings for several hundred magisterial districts.

The WCC estimates that his report for a specific year's accidents becomes available 31 to 36 months after the end of that year (see e.g. introductory chapter in the 1998 report). In practice, however, this target is often exceeded. When Lerer and Myers (1994) conducted a study on underreporting 1991-1993, the most recent WCC report was for 1988 (5 years lag). In 2000, the most recent report was for 1995 (5 years lag). In early 2012, the most recent report is for 1999 (11 years lag).

Statistics on occupational accidents are recognized tools for measuring performance and guiding preventive policies and campaigns (ILO 1996). Timely availability of data is important for such feedback to be effective. The ambitious nature of the WCC reporting format delays publication; for instance costs can only be determined when treatment of injuries is complete and all medical compensation claims processed. Administrative issues may also play a role. Critics say the WCC experiences a massive administrative logjam with a back$\log$ of 198,000 case-files, 100,000 pieces of unopened mail and an average mail response time of eight months (Bell 2010).

It may be argued that a simple preliminary reporting of injury numbers and incident rates would suffice for early feedback and that prompt availability of WCC statistics could compensate for lack of detailed information on severity rates. Indeed, that the uncertainties and inaccuracies in WCC data as identified in this paper might not even warrant computation of detailed frequency rates. Alternatively, that data from DOL could serve as useful but crude indicators, refer to regression equation 3 .

\subsection{No clear evidence of effects of labour market restructuring}

There is a growing body of evidence of a restructuring taking place in the South African labour market towards increased use of subcontracting and towards converting permanent employees into free-lance contractors, the so-called 'independent contractor' arrangements (Hedlund 2011). The practice of replacing permanent workers with contract workers is widespread in the mining industry (Bezuidenhout 2008). Barchiesi (2010) states that casual, fixed-term, part-time, and homework arrangements are on the rise across the whole occupational spectrum in South Africa, facilitated by increased use of labour brokerage. Theron (2005) views the increase in the numbers of persons in non-standard employment as a result of processes of externalisation, mainly because a stan- 
dard employment relationship entails labour regulation compliance costs and rigidities associated with worker protection rights. Employment in the informal sector doubled from 1997 to 2003; employment in informal enterprises seem to be concentrated in trade and with significant numbers of people in construction and manufacturing (Devey et al. 2006).

The exclusion of the self-employed and of independent contractors from the compensation statistics is neither trivial nor insignificant. Self-employed workers cannot or do not make worker's compensation claims and their injuries may not be picked up by reporting requirements under OHS legislation either (Mayhew and Quinlan 1997). Effects of such restructuring will be masked, understated or missing entirely from statistics derived from worker's compensations claims data (Quinlan 1999, Quinlan and Mayhew 1999).

Injuries amongst the self-employed are out scope WCC statistics but still reportable to the DOL. A change in the difference between the two sources might therefore indicate that an increasing number of injuries from this group are systematically lost in the WCC statistics. Examination of Figure 2 (fatal) and in particular Figure 3 (permanent disablement), and the incidence rate equivalents, Figure 5 and Figure 6, could indicate such a development for the late 1990s. Unfortunately, the very few data points and the obvious validity issues with a large (unexplained) number of repudiated cases impede any firm conclusions. 


\section{Conclusion}

Despite substantial scope differences between accidents registered with the Workmen's Compensation Commissioner (WCC) insurance system and the legislative Department of Labour (DOL) system, analysis show that the data are in broad agreement.

The DOL system is simple and data are typically available for DOL's annual report released the subsequent year in June. In contrast, the WCC system is complex and the highly detailed statistical report is often released after five years, or more. This lag limits the value of WCC statistics as feedback instruments to monitor performance and guide preventive efforts. DOL data could serve as a quick, crude but nevertheless reliable feedback instrument, for instance using equation [3].

For both systems however, accident reporting appears to have ceased around year 2000. By early 2012, the most recent WCC report is for 1999, and there could be concerns about the validity of that year's data, due to an extreme number of repudiations. For the period 2000-2010, there are sporadic DOL releases of accident numbers only, and some of the data are evidently erratic. Frequent changes in the recent DOL reporting format also limit the amount of analysis that can be applied to the data.

Statistics on occupational accidents are recognized tools for measuring performance and guiding preventive policies and campaigns. At present, this kind of feedback is unavailable for South Africa. 


\section{Acknowledgements}

Much of the basic data collection and analysis work took place in South Africa 1999-2000 in the early stages of a research programme leading to a $\mathrm{PhD}$ thesis, which was co-financed by DANCED and Aalborg University. 


\section{$7 \quad$ References}

Barchiesi F (2010) Informality and Casualization as Challenges to South Africa's Industrial Unionism: Manufacturing Workers in the East Rand/Ekurhuleni Region in the 1990s. African Studies Quarterly 11(2\&3)

Bell T (2010) Compensation fund in state of disarray. The Star, Business Report, May 14, 2010.

Bezuidenhout A (2008) New patterns of exclusion in the South African mining industry. In Habib and Bentley (2008): Racial Redress and Citizenship in South Africa pp179-208 Human Sciences Research Council (www.hsrcpress.ac.za)

Devey R, Skinner C, Valodia I (2006) The state of the informal economy In: Buhlungu et al. 2006(eds.) State of the Nation: South Africa 2005-2006

Eisner HS, Leger J-P (1988a) Safety in South African mines: An analysis of accident statistics. Journal of the South African Institute of Mining and Metallurgy $88(1): 1-7$

Eisner HS, Leger J-P (1988b) The international safety rating system in South African mining. Journal of Occupational Accidents 10:141-160

Hämäläinen P, Takala J, Saarela KL (2006) Global estimates of occupational accidents Safety Science 44:137-156

Hedlund FH (2011) Cleaner Production and Workplace Health and Safety: A combined approach. A case study from South Africa. Lambert ISBN-13: 9783843394949

ILO (1996) Recording and notification of occupational accidents and diseases. An ILO code of practice. International Labour Organisation (ILO). ISBN 92-2109451

Jacinto C., Aspinwall E. (2004) A survey on occupational accidents' reporting and registration systems in the European Union. Safety Science 42:933-960

Leger (1992) "Talking rocks" - an investigation of the Pit Sense of rockfall accidents amongst underground gold miners (PhD thesis) University of the Witwatersrand, Johannesburg, South Africa 
Leger J-P (1990) Trends and causes of fatalities in South African mines. Safety Science 14(3-4):9-185

Leger J-P, Macun IA (1990) Safety in South African industry: An analysis of accident statistics. Journal of Occupational Accidents 11:197-220

Lerer LB, Myers JE (1994) Application of two secondary documentary sources to identify the underreporting of fatal occupational injuries in Cape Town, South Africa. American Journal of Industrial Medicine 26:521-527

Leon RN, Salamon MDG, Davies AW, Davies JCA (1995) Commission of inquiry into safety and health in the mining industry (Leon Commission). vol 1-2 Government Printer (Johannesburg, South Africa)

Mayhew C, Quinlan M (1997) Subcontracting and occupational health and safety in the residential building industry. Industrial Relations Journal 28(3):192-205

Murray J, Sonnenberg P, Nelson G, Shearer S, Bester A, Begley A, Glynn JR (2005) Effect of HIV on work-related injury rates in South African gold miners AIDS 19(17):2019-24 (2005 Nov 18)

Quinlan M (1999) The implications of labour market restructuring in industrialized societies for occupational health and safety. Economic and Industrial Democracy 20:427-460

Quinlan M, Mayhew C (1999) Precarious employment and workers' compensation. The International Journal of law and Psychiatry 22(5-6):491-520

Robens (Lord) (1972) Safety and health at work. Report of the committee 1970-1972. Her Majesty's stationary office, London

Takala J (1999) Global estimates of fatal occupational accidents. Epidemiology 10(5):640-646

Theron, J. 2005. Employment is not what it used to be: The nature and impact of work restructuring in South Africa. In, E.Webster and K.Von Holdt (Eds), Beyond the Apartheid Workplace. University of KwaZulu-Natal, pp. 293-316

Wiehahn NE (1980) Report of the commission of inquiry into labour legislation Part 4: Protection of the safety and health of workers in South Africa. Government Printer 
Recorded fatal and permanently disabling injuries in South African manufacturing industry - Overview, analysis and

Table $1 \quad$ Accident and employment data1970-2010 (with corrections) for the South African manufacturing sector ${ }^{a}$ used in this study

\begin{tabular}{|c|c|c|c|c|c|c|c|c|c|c|c|c|}
\hline & \multicolumn{3}{|c|}{ WCC - State Accident Fund } & \multicolumn{4}{|c|}{ WCC - All Funds ${ }^{b}$} & \multicolumn{3}{|c|}{ Department of Labour } & \multicolumn{2}{|c|}{ Employment statistics } \\
\hline Year & Workmen & Perm & Fatal & Perm & Fatal & $\begin{array}{l}\text { Vehicle } \\
\text { perm }\end{array}$ & $\begin{array}{r}\text { Vehicle } \\
\text { fatal }\end{array}$ & Workers & Incidents $^{d}$ & Fatal & Bulletin & SALS \\
\hline 1970 & $1,350,121$ & 4,751 & 259 & 4,906 & 264 & 362 & 152 & $1,292,639$ & 12,404 & 138 & $1,164,100$ & \\
\hline 1971 & $1,345,853$ & 4,911 & 268 & 5,036 & 287 & 394 & 133 & $1,381,514$ & 14,326 & 167 & $1,202,500$ & $1,107,000$ \\
\hline 1972 & $1,297,394$ & 4,869 & 278 & 5,002 & 301 & 386 & 154 & $1,410,738$ & 14,568 & 186 & $1,228,000$ & $1,127,275$ \\
\hline 1973 & $1,537,225$ & 5,126 & 326 & 5,329 & 335 & 419 & 163 & $1,478,817$ & 16,572 & 205 & $1,171,300$ & $1,189,000$ \\
\hline 1974 & $1,614,891$ & 5,201 & 307 & 5,381 & 317 & 445 & 132 & $1,569,053$ & 16,369 & 211 & $1,233,900$ & $1,259,800$ \\
\hline 1975 & $1,637,852$ & 5,012 & 332 & 5,182 & 338 & 382 & 159 & $1,602,196$ & 18,650 & 188 & $1,254,100$ & $1,307,600$ \\
\hline 1976 & $1,555,501$ & 4,748 & 271 & 4,889 & 275 & 338 & 125 & $1,634,854$ & 16,937 & 172 & $1,355,205$ & $1,355,205$ \\
\hline 1977 & $1,545,003$ & 4,232 & 244 & 4,350 & 252 & 283 & 104 & $1,497,835$ & 14,166 & 160 & $1,323,800$ & $1,317,200$ \\
\hline 1978 & $1,491,320$ & 3,879 & 245 & 4,026 & 249 & 287 & 112 & $1,534,045$ & 14,068 & 148 & $1,325,400$ & $1,312,100$ \\
\hline 1979 & $1,553,902$ & 3,901 & 176 & 3,992 & 178 & 247 & 74 & $1,588,815$ & 15,182 & 170 & $1,352,200$ & $1,332,743$ \\
\hline 1980 & $1,529,637$ & 4,614 & 292 & 4,728 & 293 & 305 & 141 & $1,676,923$ & 15,673 & 185 & $1,411,400$ & $1,421,400$ \\
\hline 1981 & $1,333,697$ & 4,462 & 277 & 4,556 & 281 & 283 & 132 & $1,814,941$ & 14,731 & 189 & $1,468,400$ & $1,508,322$ \\
\hline 1982 & $1,634,619$ & 4,168 & 256 & 4,272 & 259 & 279 & 111 & $1,887,423$ & 13,623 & 169 & $1,473,700$ & $1,542,618$ \\
\hline 1983 & $1,475,075$ & 3,708 & 179 & 3,867 & 181 & 277 & 84 & & 12,490 & 182 & $1,392,000$ & $1,465,827$ \\
\hline 1984 & $1,728,862$ & 3,906 & 201 & 3,994 & 202 & 247 & 76 & & 11,241 & 161 & $1,399,400$ & $1,477,940$ \\
\hline 1985 & $1,527,076$ & 3,357 & 187 & 3,444 & 189 & 202 & 97 & & 5,266 & 110 & $1,326,900$ & $1,428,988$ \\
\hline 1986 & $1,540,586$ & 3,796 & 233 & 3,908 & 234 & 275 & 112 & & 4,916 & 107 & $1,313,500$ & $1,442,892$ \\
\hline 1987 & $1,603,031$ & 3,935 & 197 & 3,998 & 202 & 269 & 111 & & 4,830 & 106 & $1,427,800$ & $1,482,640$ \\
\hline 1988 & $1,876,278$ & 4,231 & 221 & 4,304 & 246 & 256 & 111 & & 5,161 & 116 & $1,448,500$ & $1,530,693$ \\
\hline 1989 & $1,810,726$ & 4,299 & 254 & 4,373 & 259 & 268 & 123 & & & & $1,458,800$ & $1,531,072$ \\
\hline 1990 & $1,816,071$ & 4,346 & 231 & 4,377 & 233 & 257 & 115 & & 4,935 & 93 & $1,462,118$ & $1,525,208$ \\
\hline 1991 & & 3,944 & 211 & 3,979 & 214 & 212 & 77 & & 4,666 & 99 & $1,484,342$ & $1,484,342$ \\
\hline 1992 & & 3,556 & 223 & 3,560 & 225 & 223 & 96 & & 4,516 & 96 & $1,436,409$ & $1,438,409$ \\
\hline 1993 & & 3,210 & 203 & 3,212 & 207 & 193 & 81 & & 3,763 & 114 & $1,405,552$ & $1,405,552$ \\
\hline 1994 & $1,542,703$ & 3,495 & 309 & 3,499 & 309 & 240 & 122 & & 4,250 & 126 & $1,399,513$ & $1,399,513$ \\
\hline 1995 & $1,683,351$ & 3,598 & 264 & 3,603 & 264 & 252 & 123 & & 4,975 & 127 & $1,417,398$ & \\
\hline 1996 & $1,752,624$ & 3,528 & 256 & 3,555 & 257 & 251 & 124 & & 4,804 & 115 & $1,433,649$ & \\
\hline 1997 & $1,633,954$ & 2,887 & 197 & 2,908 & 197 & 183 & 100 & & 3,151 & 72 & $1,395,636$ & \\
\hline 1998 & $1,583,766$ & 2,602 & 192 & 2,617 & 197 & 126 & 76 & & 3,166 & 90 & $1,339,888$ & \\
\hline 1999 & $1,424,180$ & 1,818 & 125 & 1,826 & 126 & 91 & 53 & & 4,975 & 84 & $1,314,488$ & \\
\hline 2000 & & & & & & & & & & & $1,306,795$ & \\
\hline 2001 & & & & & & & & & & & $1,259,672$ & \\
\hline 2002 & & & & & & & & & & & $1,261,309$ & \\
\hline 2003 & & & & & & & & & 1,200 & 51 & $1,237,015$ & \\
\hline 2004 & & & & & & & & & 355 & $25^{\mathrm{e}}$ & $1,265,358$ & \\
\hline 2005 & & & & & & & & & & & $1,182,056$ & \\
\hline 2006 & & & & & & & & & & & $1,331,332$ & \\
\hline 2007 & & & & & & & & & & & $1,323,498$ & \\
\hline 2008 & & & & & & & & & 543 & 38 & $1,306,588$ & \\
\hline 2009 & & & & & & & & & & & $1,219,846$ & \\
\hline 2010 & & & & & & & & & & & & \\
\hline
\end{tabular}

Notes

a Number of accidents in the manufacturing sector are computed in the following manner. For WCC data and DOL data after 1984 the sum of Standard Industrial Classification (SIC) category 6-14 is computed. For DOL 
data before 1985. figures are computed as the sum of category 1-8 minus sub-category 8e ("non-factory"), which appears to be similar to the procedure used by Leger and Macun (1990).

b If the reported number for All Funds is lower than for the SAF, the SAF number is used, this correction done for 1971, 1972, 1976, 1978, 1991, 1993, 1995 and 1997

c Reporting scope changed $1984 / 85$ to follow SIC codes

d Incidents are reportable if they result in specified length of absence from work, in permanent disablement, if a dangerous substance was spilled, amongst others. Length of absence from work criterion changed with the MOSA Act of 1983

e $\quad$ See Table 3 for a discussion of DOL data 1991-2010 
Table 2 Repudiations per category ${ }^{a}$ for the State Accident Fund 1970-1999
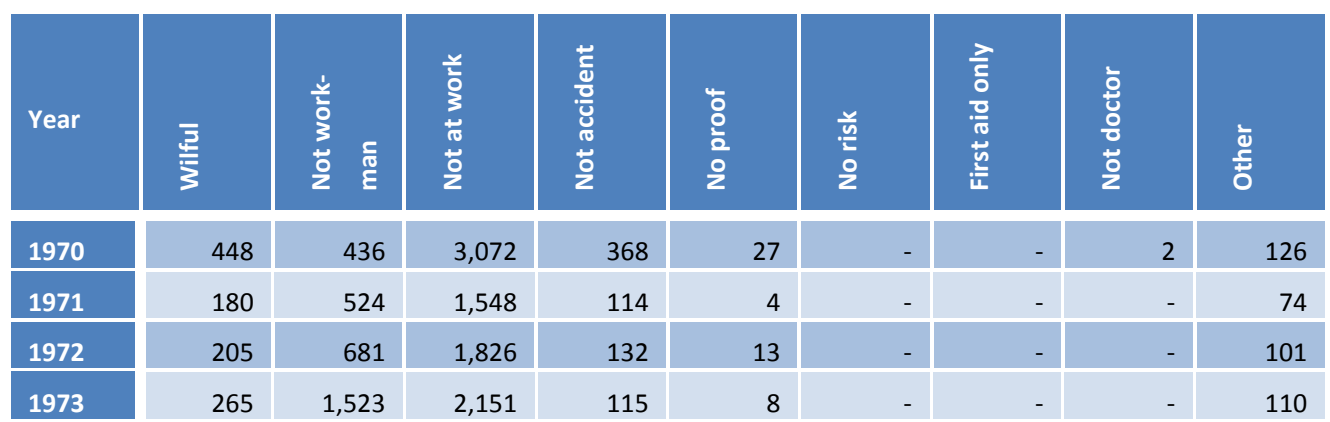

\begin{tabular}{|l|l|l|}
\hline 448 & 436 & 3,072 \\
\hline 180 & 524 & 1,548 \\
\hline 205 & 681 & 1,826 \\
\hline
\end{tabular}

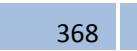

27
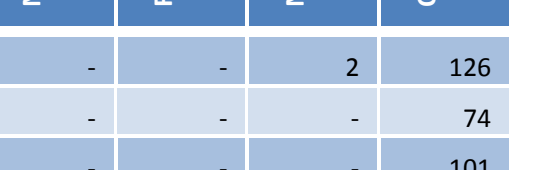

1974

\begin{tabular}{|r|r|r|}
\hline 265 & 1,523 & 2,151 \\
\hline
\end{tabular}

114

4

$-$

132

1975

\begin{tabular}{|l|l|l|}
\hline 333 & 1,014 & 1,782 \\
\hline
\end{tabular}

115

\section{6}

\begin{tabular}{|l|l|r|}
\hline 440 & 1,370 & 1,960 \\
\hline
\end{tabular}

91

8

\begin{tabular}{l|l|l|}
\hline 451 & 3,387 & 2,075 \\
\hline
\end{tabular}

\begin{tabular}{|r|}
94 \\
\hline 83
\end{tabular}

1977

1978

1979

1980

1981

1982

1983

1984

1985

1986

1987

1988

1989

1990

1991

1992

1993

1994

$1995^{\mathrm{b}}$

1996

1997

1998

1999

\begin{tabular}{|r|r|r|r|}
\hline 538 & 2,096 & 2,508 \\
\hline 583 & 955 & 2,995 \\
\hline
\end{tabular}

,995

91

2

200

1

\begin{tabular}{|l|l|l|}
\hline 393 & 2,083 & 1,943 \\
\hline 479 & 4,618 & 2,194 \\
\hline
\end{tabular}

200

$-$

\begin{tabular}{|l|l|l|}
\hline 305 & 4,565 & 1,617 \\
\hline 218 & 4,984 & 1,413 \\
\hline
\end{tabular}

$264 \quad 2$

276

1

\begin{tabular}{|l|l|l|l|l|}
\hline 230 & 5,099 & 1,275 & 238 & 1 \\
\hline 212 & 2,882 & 1,321 & 342 & - \\
\hline 188 & 2,790 & 1,337 & 393 & 1 \\
\hline 115 & 1,299 & 1,470 & 478 & 3 \\
\hline 126 & 1,813 & 1,325 & 434 & 6 \\
\hline 127 & 829 & 1,381 & 452 & 1,413 \\
\hline
\end{tabular}

264

1

\begin{tabular}{|r|r|r|r|r|}
\hline 126 & 1,813 & 1,325 & 434 & 6 \\
\hline 127 & 829 & 1,381 & 452 & 1 \\
\hline 144 & 1,410 & 1,254 & 454 & 46 \\
\hline 118 & 3,582 & 1,396 & 487 & 14 \\
\hline
\end{tabular}

\begin{tabular}{|l|l|l|}
\hline 118 & 3,582 & 1,396 \\
\hline 129 & 3,692 & 1,951 \\
\hline 106 & 3,332 & 1,938 \\
\hline
\end{tabular}

\begin{tabular}{|l|l|}
\hline 754 & 60 \\
\hline 585 & 59 \\
\hline
\end{tabular}

\begin{tabular}{|r|r|r|}
\hline 104 & 2,550 & 1,630 \\
\hline 72 & 623 & 1,734 \\
\hline
\end{tabular}

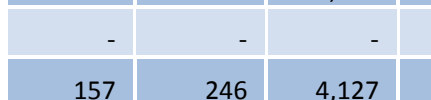

\begin{tabular}{|l|l|}
\hline 623 & 56 \\
\hline 659 & 42 \\
\hline
\end{tabular}

42

\begin{tabular}{r|r}
- & - \\
\hline 1,783 & 276 \\
\hline
\end{tabular}

\begin{tabular}{|r|}
\hline- \\
\hline 1 \\
\hline 1 \\
\hline 2 \\
\hline 62
\end{tabular}

a Repudiation categories are: Wilful misconduct, Not a workman, Not arising out of or in the course of employment, Not an accident (gradual onset etc), Not sufficient proof to accept, Not specifically exposed to extra risk, First aid only, Treated by a person other than a reg. practitioner (Source: WCC Annual Report on the Statistics, table C)

b Repudiations not reported 
Table 3 Overview of accident data available in DOL publications

\begin{tabular}{|lllll|}
\hline Year & DOL Annual Report & Year & DOL Annual Report & Labour Market Bulletin \\
\hline 1991 & No data & $\mathbf{2 0 0 1}$ & Report unavailable at DOL & \\
\hline 1992 & No data & $\mathbf{2 0 0 2}$ & Report unavailable at DOL & \\
\hline 1993 & No data & $\mathbf{2 0 0 3}$ & No data & 2003-2004, new format, \\
\hline 1994 & No data & $\mathbf{2 0 0 4 d}$ & No data & evident discrepancies \\
\hline 1995 & $1991-1995$ & & & Report unavailable at DOL \\
\hline $1996^{\text {b }}$ & $1992-1996$, new format & 2005 & No data & Totals only \\
\hline 1997 & $1993-1997$ & $\mathbf{2 0 0 6}$ & No data & Totals only \\
\hline $1998^{\text {c }}$ & $1994-1998$, new format & $\mathbf{2 0 0 7}$ & No data & 2008 \\
\hline 1999 & $1995-1999$ & $\mathbf{2 0 0 8}$ & No data & No data \\
\hline $\mathbf{2 0 0 0}$ & No data & $\mathbf{2 0 0 9}$ & No data & No data \\
\hline
\end{tabular}

a First issue of Labour Market Bullet in 2004

${ }^{b}$ Reporting format changed to an alphabetical listing, not per SIC category, and some categories change name, e.g. SIC 8 "Wood" becomes "Timber", potentially confusing it with SIC 1 "Agriculture and forestry"

c The reported fatal accidents for 1996 changed from 94 to 115, for 1997 from 70 to 72 . The changes are unnoticed in the report and could be typos, the new numbers are carried over in later reports and used here

${ }^{d}$ The reporting format changes: new terms: casualties, non-casualties, fatalities, nonfatalities are introduced. New category "Private households" introduced. Table 38 and 39 provide breakdowns per industry and per province, but sums do not align, gross discrepancies. 


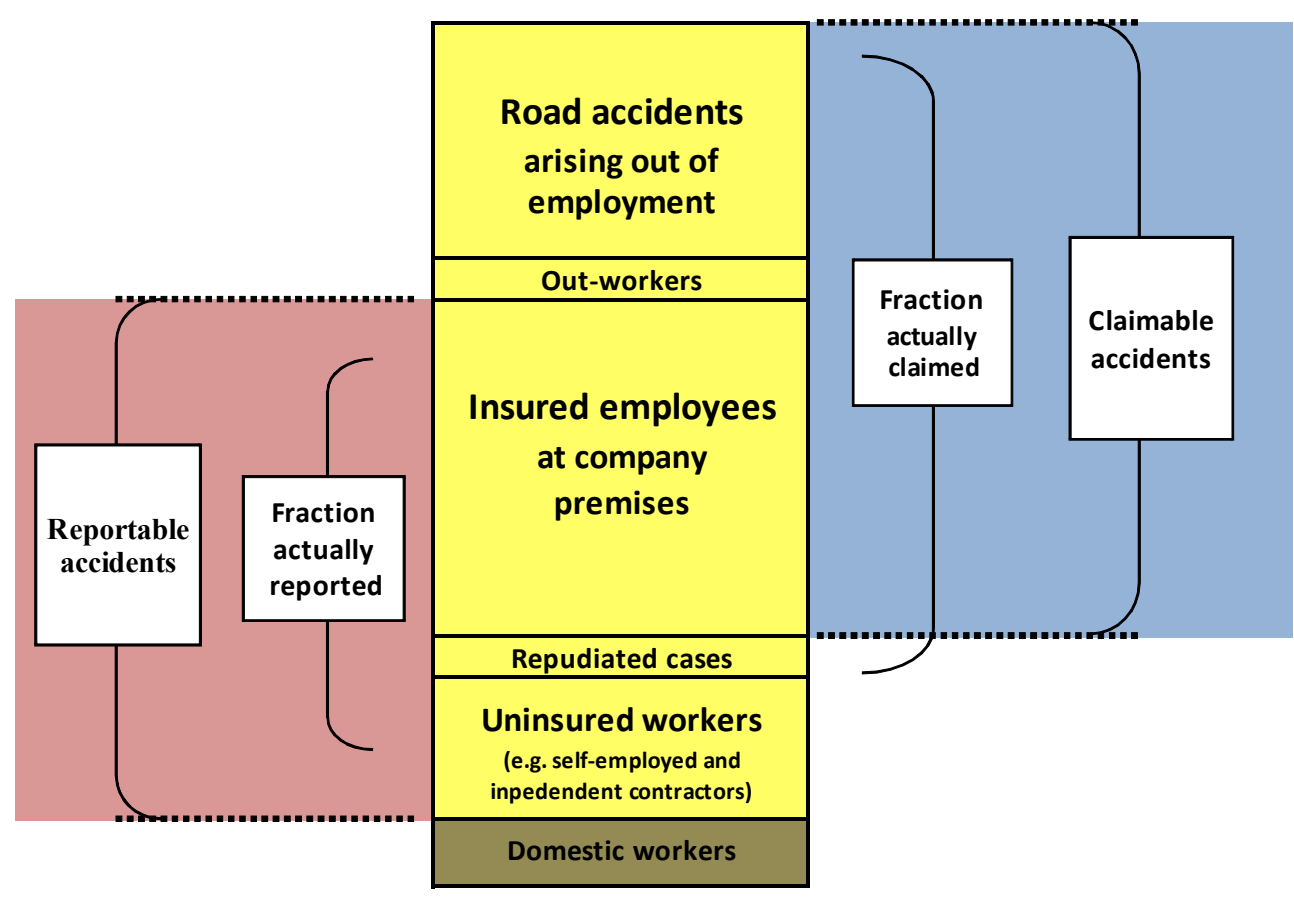

Figure $1 \quad$ Scope of South African fatal accident statistics from the OHS reporting and insurance systems. 


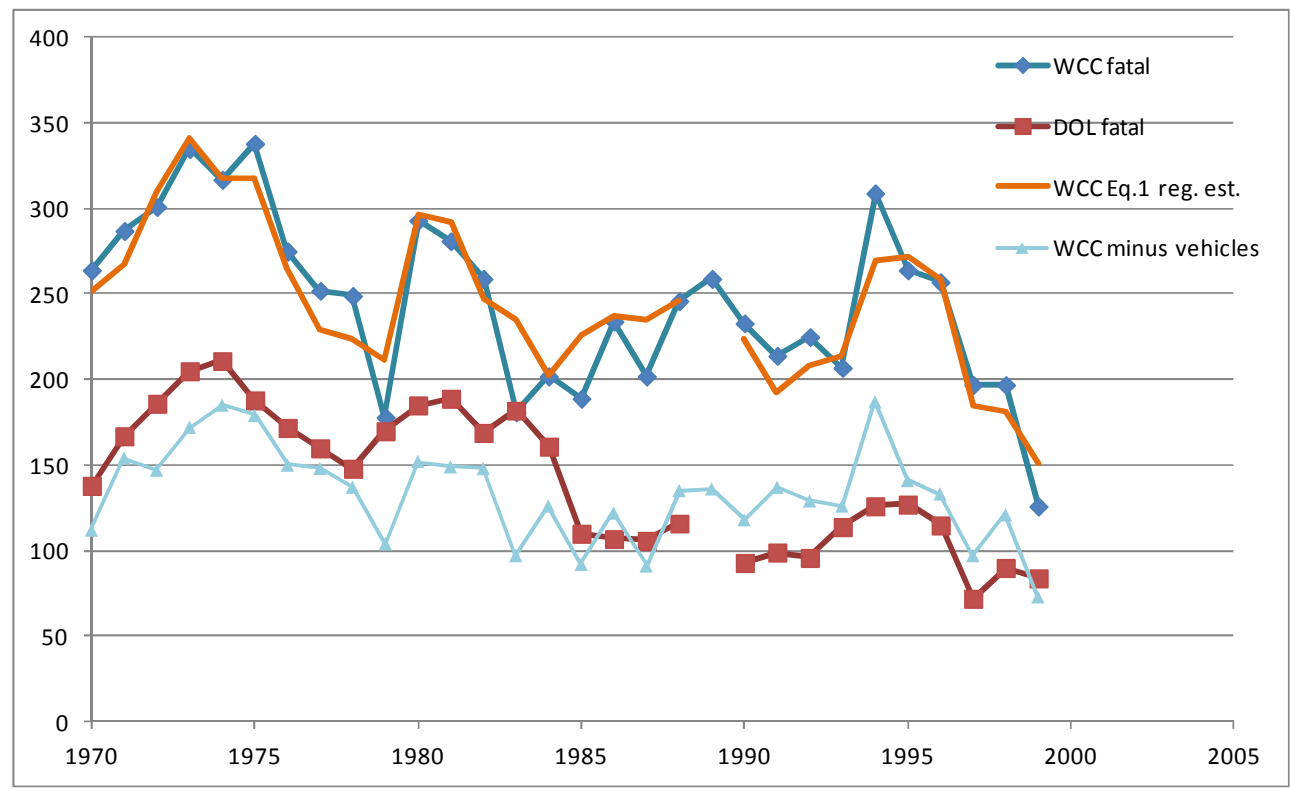

Figure 2 Number of fatal accidents per year in manufacturing reported to the Workmen's Compensation Commissioner (WCC) for All Funds, fatal accidents reported to the Department of labour (DOL), and predicted WCC fatal accidents using regression equation 1 (see text) 


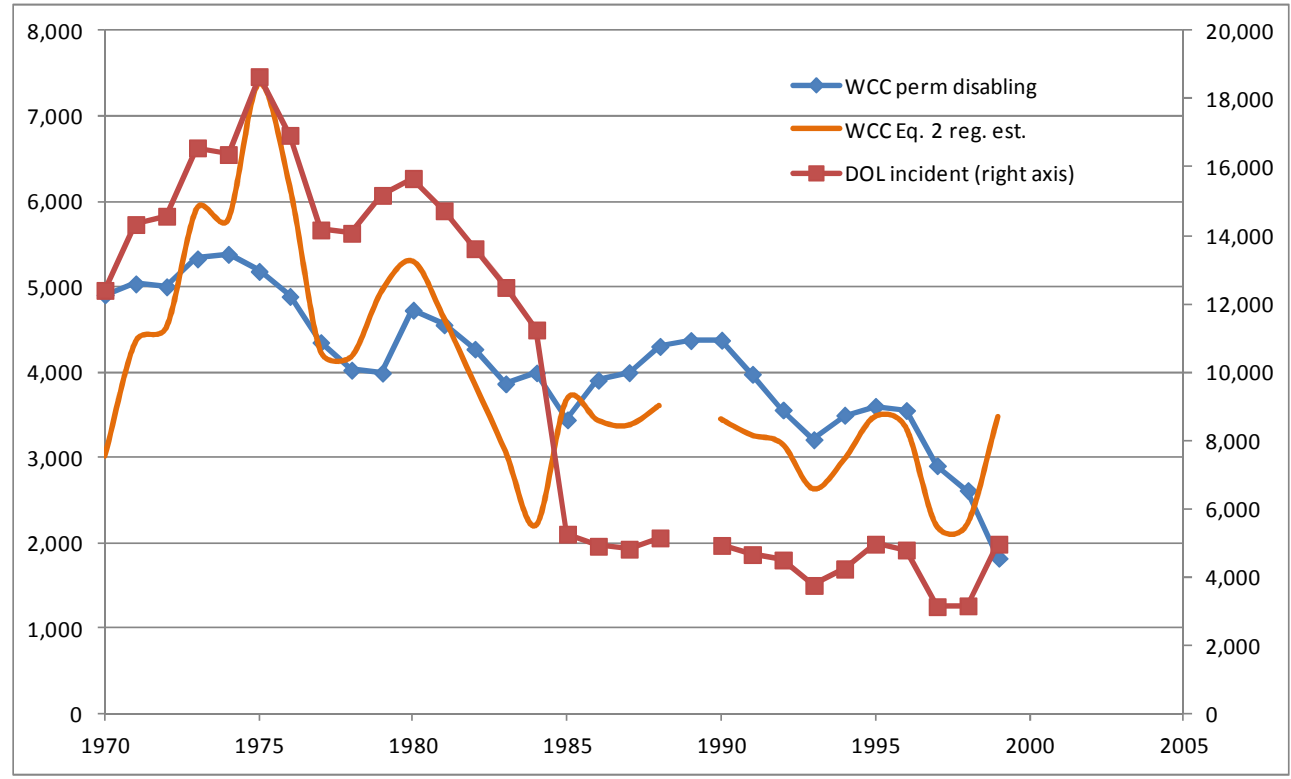

Figure $3 \quad$ Number of permanently disabling injuries per year in manufacturing reported to the Workmen's Compensation Commissioner (WCC) for All Funds, reportable incidents/casualties reported to the Department of labour (DOL), and predicted WCC permanently disabling injuries using regression equation 2 (see text) 


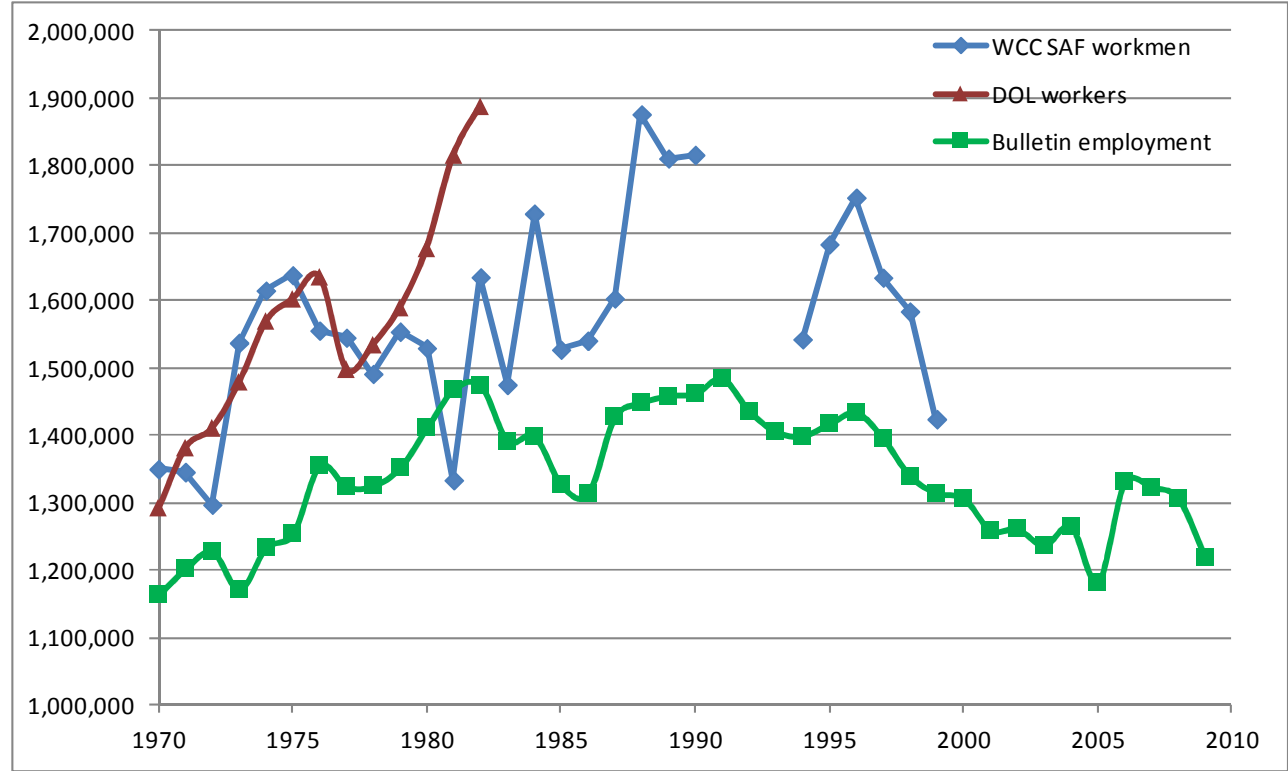

Figure $4 \quad$ Number of insured workmen in manufacturing reported to the Workmen's Compensation Commissioner (WCC) (State Accident Fund only), number of workers reported to the Department of labour (DOL) (discontinued in 1983) and employment figures published in the quarterly Bulletin by Statistics South Africa (SSA). Note that vertical axis starts with 1 million employees. 


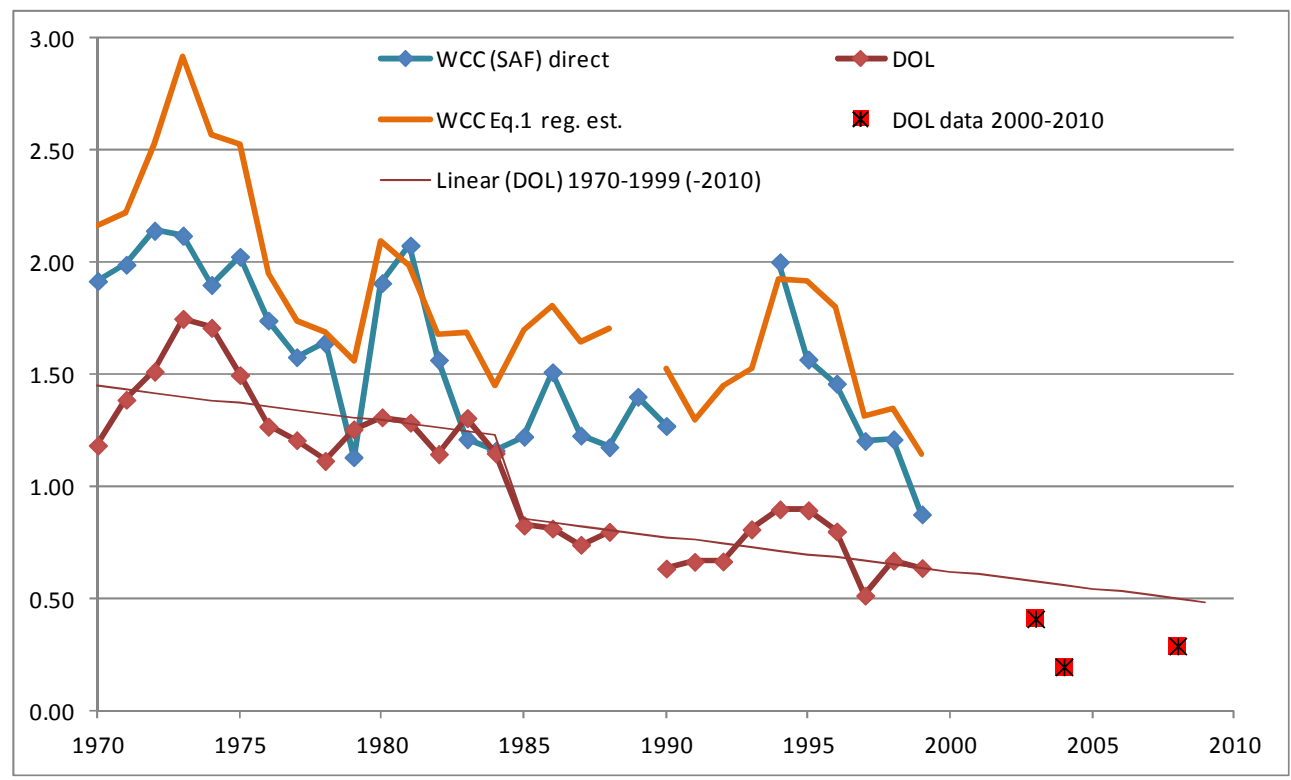

Figure $5 \quad$ Three series of fatal incidence rates per 10,000 employees for manufacturing. Rates are computed directly from State Accident Fund (SAF) data, from Department of labour (DOL) data (extrapolated to 2010) and from a revised estimate for Workmen's Compensation Commissioner, All Funds, using regression equation 1 and official employment data. . 


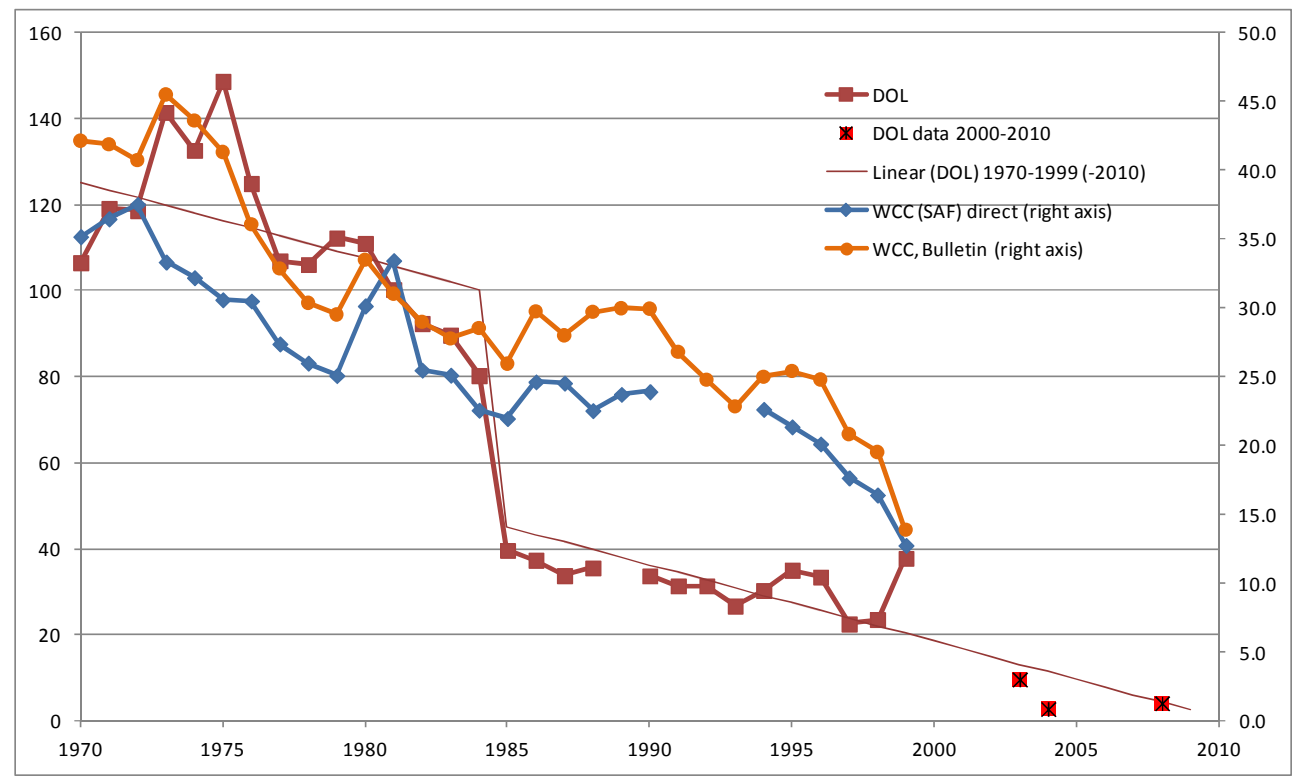

Figure $6 \quad$ Permanently disabling injury incidence rates per 10,000 employees for manufacturing computed directly from WCC State Accident Fund (SAF) data, for WCC (All Funds) data and Bulletin employment, and rates for reportable "incidents/casualties" from Department of labour (DOL) data and Bulletin employment with superimposed and extrapolated regression line (equation 5). DOL data are left axis, SAF data right axis. 